\title{
Assessment of technical parameters and skills training to inform a simulation-based training program for semi-automated robotic colonoscopy
}

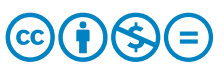

\author{
Authors \\ Xujiong $\mathrm{Ye}^{3}$, Sunil Dolwani ${ }^{1}$ \\ Institutions \\ 1 Cardiff University School of Medicine, Cardiff, Wales \\ 2 Welsh Institute for Minimal Access Therapy (WIMAT), \\ Cardiff University, Cardiff, Wales \\ 3 University of Lincoln, School of Computer Science, \\ London, UK \\ 4 Cardiff and Vale University Health Board, Penarth, \\ Cardiff, Wales
}

Maja Kopczynska ${ }^{1}$, Stephanie Smits ${ }^{1}$, Rebecca Hopps ${ }^{4}$, Rajeswari Ramaraj ${ }^{1}$, Neil Warren², Stuart Goddard²,

submitted 9.2.2018

accepted after revision 25.4 .2018

Bibliography

DOI https://doi.org/10.1055/a-0774-4554 |

Endoscopy International Open 2019; 07: E9-E14

(c) Georg Thieme Verlag KG Stuttgart · New York

ISSN 2364-3722

Corresponding author

Sunil Dolwani, Cardiff University, Division of Population

Medicine, Department of Gastroenterology, University

Hospital Llandough, Penlan Road, Penarth, Cardiff, UK CF64

2XX

Fax: +442920715538

Dolwanis@cardiff.ac.uk

\section{ABSTRACT}

Background and study aims Video-colonoscopy, despite being the gold-standard for diagnosis of colorectal lesions, has limitations including patient discomfort and risk of complications. This study assessed training characteristics and acceptability in operators of a new robotic colonoscope (RC).

Materials and methods Participants $(n=9)$ with varying degrees of skill and background knowledge in colonoscopy performed colonoscopies with a RC on a simulation-based training model. Quantitative procedure-related and qualitative operator-related parameters were recorded.

Results Polyp detection rate was highest in the novice group ( $91.67 \%$ ) followed by experts ( $86.11 \%$ ), then equally, trainees and video gamers (79.17\%). Four participants repeated the procedure at a follow-up session. Each participant improved cecal intubation time and had the same or higher polyp detection rate. The potential role for RC was identified for an out-of-hospital environment and as a novel diagnostic tool.

Conclusions Results from this pilot suggest that operators at all skill levels found the RC acceptable and potentially useful as a diagnostic tool. Acquisition of skills with RC seems to improve rapidly to a clinically relevant level with simulation-based training

\section{Introduction}

Colorectal cancer (CRC) has one of the highest incidences of all cancers in the developed world [1]. CRC screening and early diagnosis have proven benefit in numerous international largescale, population-based studies and secondary care-based retrospective case control studies. [2,3]. Currently, video-colonoscopy is considered the gold standard for diagnosis of colorectal neoplasia [4]. There are, however, important limitations of this technique, including invasiveness, patient discomfort and risk of complications $[5,6]$.

Trainees entering colonoscopy training programs face a challenging and long skill acquisition process in order to ac- quire an appropriate level of dexterity and lesion recognition. According to some studies, changing to non-conventional modalities integrating robotic technology with imaging for colonoscopy may influence patient comfort, compliance as well as health professional and resource demand [7]. New developments within robotic technology include disposable probes that have potential to be safer and less painful while improving infection control and reducing costs associated with decontamination services. This may enable early diagnosis of colorectal pathology in primary care as a result of better engagement with patients. The robotic colonoscope (RC) is also designed have a more intuitive steering mechanism than standard colonoscopy, which may facilitate a more approachable diagnostic skill ac- 


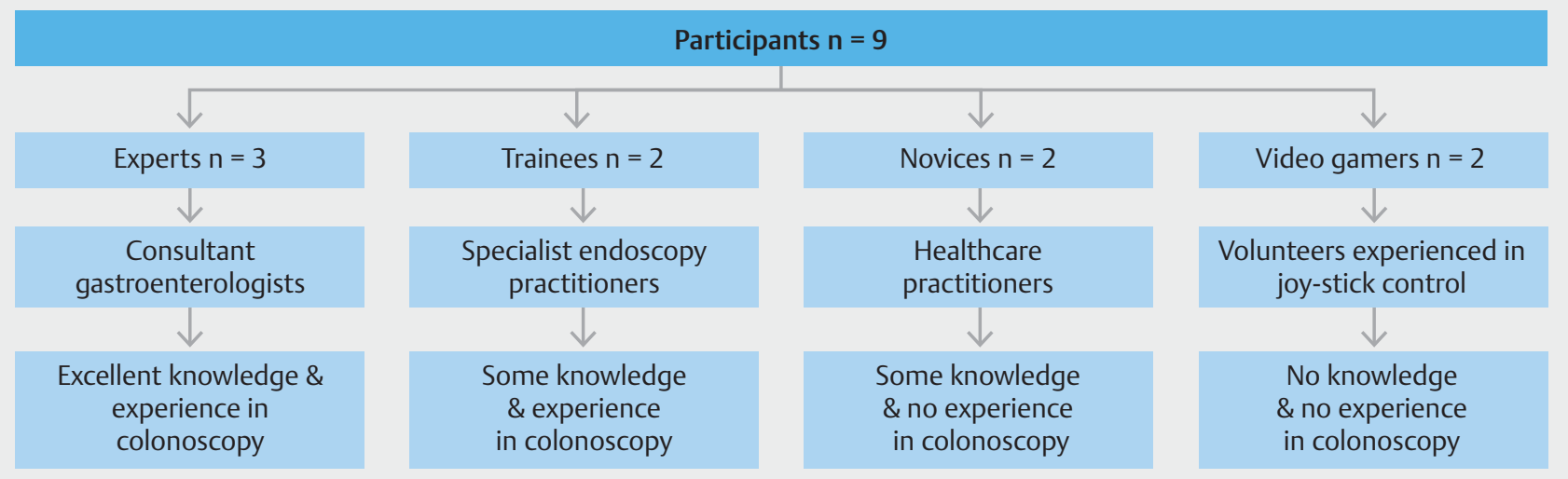

Fig. 1 Distribution of study participants.

quisition process for colonoscopists [8] and enable health professionals to make a diagnosis in the community or primary care setting.

In this study we assessed the operator acceptability of the new RC with use of a simulation-based training model. We also investigated the time taken for acquisition of skills by the participants performing RC.

\section{Materials and methods}

\section{Participants}

Invitations to participate in the study were sent out to health professionals with varying degrees of experience and expertise in colonoscopy who were from the hospital administrative and teaching facilities at Cardiff and Vale University Health Board, Wales. The participants were split into groups of different knowledge, skill and hand-eye coordination abilities. Distribution of the participants $(n=9)$ is shown in $>$ Fig. $\mathbf{1}$. We enrolled three expert endoscopists - consultant gastroenterologists, all with individual experience of a few thousand colonoscopies. The trainees with the intermediate level of endoscopic knowledge and skills were two specialist endoscopic nurses. The two novices (with knowledge and related skills but no colonoscopic skills from training or practice) included a nurse performing upper gastrointestinal endoscopies and a nurse performing capsule endoscopies. We also recruited two participants with no endoscopy knowledge or skills but who were adept in video games with joy-stick control.

\section{Robotic colonoscope}

All procedures were performed with an Endotics disposable probe [9]. The Endotics System is composed of a disposable probe and a workstation ( $\mathbf{F i g . 2}$ ). The workstation enables the endoscopist to fully control the disposable probe with a hand-held console and visualize the lumen on screen with realtime images. With the hand-held console and via the motor, the colonoscopist is able to steer the robotic colonoscope in every direction, elongate the body of the probe to move it forward, and apply rinsing, insufflation, and suction. The option to cap-

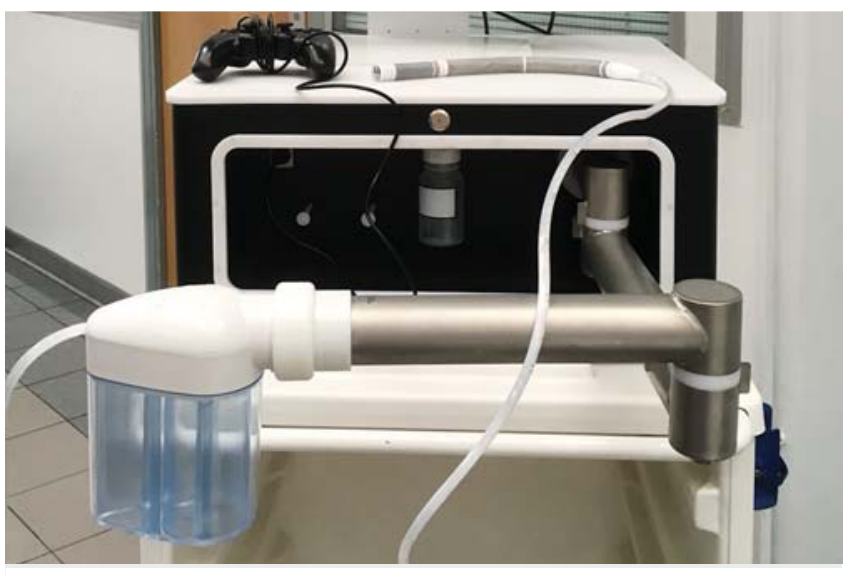

Fig. 2 The robotic colonoscope: the workstation with the probe attached.

ture images, record videos and obtain biopsies is also available. The aim of the initial testing was to evaluate tip control and precision skills, therefore, more advanced procedures such as polyp resection were not assessed. That will be addressed in a follow-up study for which patient recruitment has been completed.

\section{Study design}

All nine participants performed a colonoscopy with the RC on an adapted "colonoscopy suitcase" model developed at the Welsh Institute for Minimal Access Therapy (WIMAT) center. This model has previously been validated and used in training in diagnostic and therapeutic colonoscopy on numerous courses in the UK over the past 5 years and provides a realistic luminal appearance [10]. The colon was of the same standard length for all procedures. Twelve polyps were placed around the colon: one in the rectum, three in the sigmoid, two in the descending colon, one in the splenic flexure, two in the transverse colon, one in the hepatic flexure, one in the ascending colon and one in the cecum. All polyps were of similar size and morphologyflat circular or flat angular lesions. 


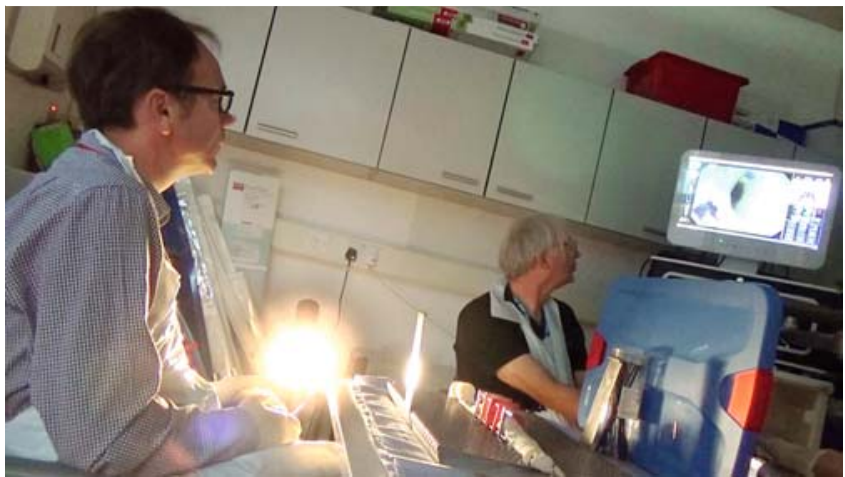

- Fig. 3 Participant performing the procedure. The "training model" used during the familiarization period is visible on the table in front of the blue screen. The adapted "colonoscopy suitcase" is placed behind the screen to decrease availability of additional visual cues for the participant.

Before testing, each participant received both verbal and written instructions on the goals of the study and information about the semi-automated RC along with a familiarization period with the device on a "training model" ( $>$ Fig. 3). Afterwards participants filled out an in-house-developed questionnaire evaluating the RC. Of nine invited participants, four participated in a follow-up session to analyze skill acquisition. The time interval between the initial and follow-up session was either 6 or 7 days, during which time the participants had no opportunity to practice the RC.

\section{Study end points}

Study end points were cecal intubation time, withdrawal time and number of detected lesions on insertion and withdrawal. Participants' evaluation of the RC was assessed with a qualitative questionnaire using closed and short answer questions.

\section{Results}

\section{Procedure characteristics}

On average, experts required a shorter time to intubate the cecum with mean 29 minutes 58 seconds, followed by video gamers (41 min $04 \mathrm{sec}$ ), trainees (44 min $28 \mathrm{sec}$ ) and novices (50 min $10 \mathrm{sec}$ ), however, there was wide variation within most groups ( $\triangleright$ Fig.4). Video gamers had the shortest withdrawal time with mean 13 minutes 31 seconds, followed by experts (18 min $26 \mathrm{sec}$ ), trainees (19 min $47 \mathrm{sec}$ ) and novices (27 min $52 \mathrm{sec})(\triangleright$ Fig. 4$)$.

\section{Polyp detection}

The overall polyp detection rate $(84.26 \%)$ was the highest in the novice group (91.67\%) followed by the experts $(86.11 \%)$ ( $\triangleright$ Fig.5). Both trainee and video gamer groups had a slightly lower polyp detection rate of $79.17 \%$. For eight of nine participants, polyp detection was higher during the scope withdrawal than during scope insertion. The most commonly missed polyps were placed in the transverse colon ( $41 \%$ of all missed polyps) and sigmoid colon (35\%). The rest of the missed polyps were placed in the rectum (12\%) and splenic flexure (12\%).

\section{Follow-up session}

Four of nine participants attended the follow-up session where they were asked to repeat the procedure. No additional information about the RC and no assistance with the joy-stick controller functions was provided during the follow-up session. During follow-up, all of the participants improved their performance. Each participant had a lower cecal intubation time during the follow-up session than in the initial session as well as the same or higher polyp detection rate ( $\vee$ Fig. $\mathbf{6})$.
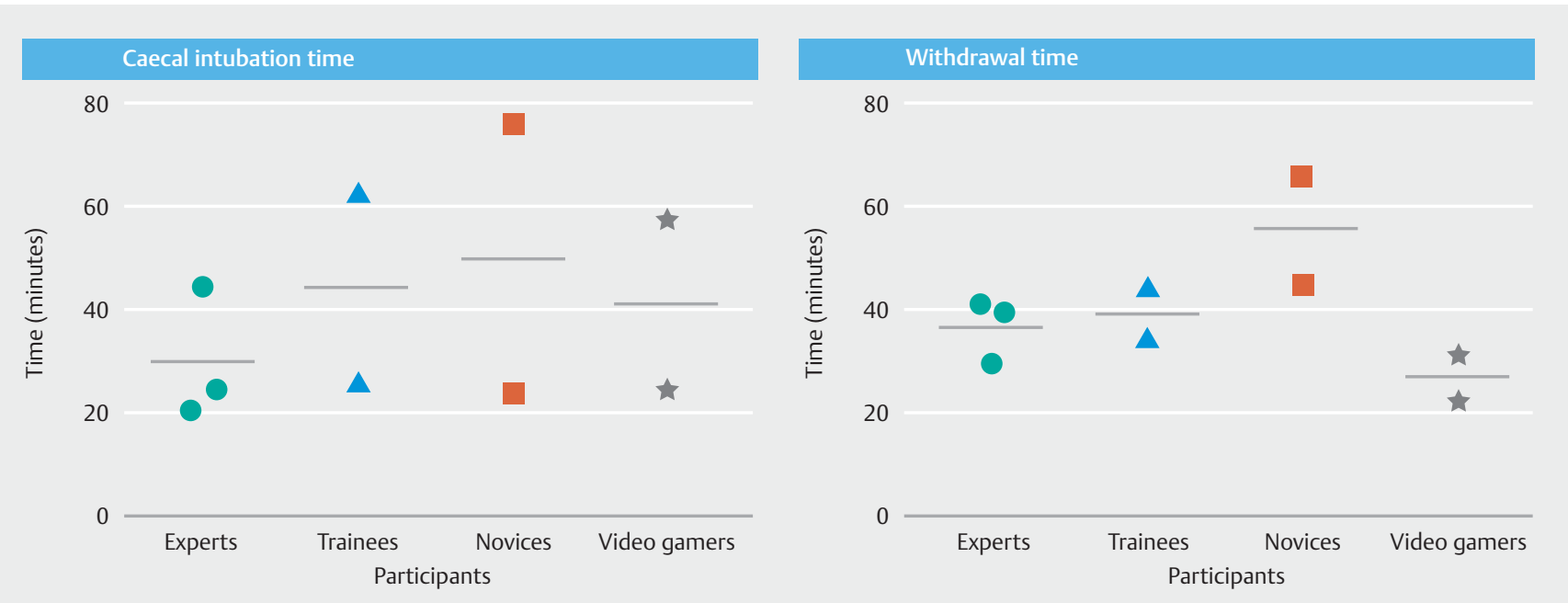

- Fig. 4 Scatter plots with cecal intubation and withdrawal times for different participant groups. Each mark demonstrates performance of a single participant. The horizontal line represents the mean time for each participant group. Circle, expert; triangle, trainee; square, novice; star, video gamer. 


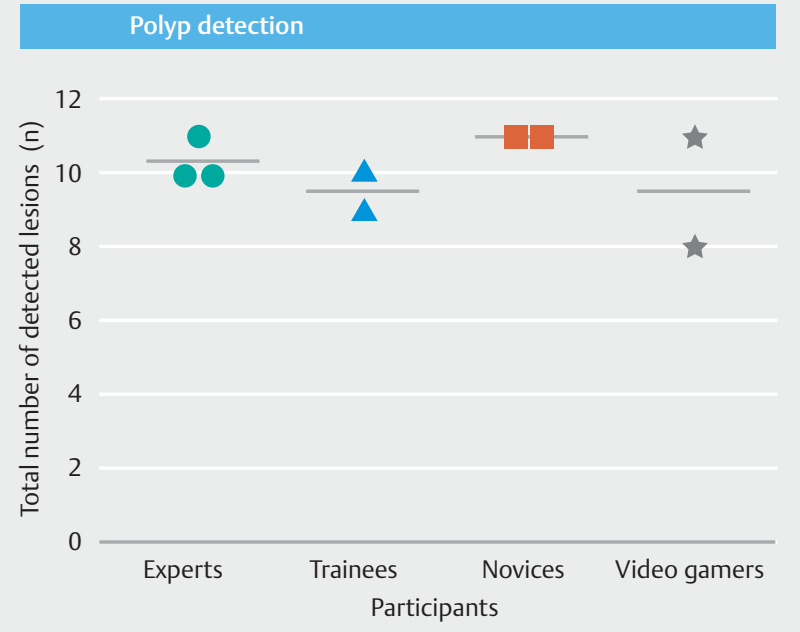

- Fig. 5 Scatter plot presenting the total polyp detection rate for participants. A rate of $100 \%$ equals detection of 12 simulated polyps. Each mark demonstrates performance of a single participant. The horizontal line represents the mean detection rate for each participant group. Circle, expert; triangle, trainee; square, novice; star, video gamer.

\section{Questionnaire evaluation}

After completing the procedure, participants filled out a questionnaire evaluating the RC. ₹ Table 1 shows the participants' views on future use of RC, with the majority of the participants perceiving a potential role for $\mathrm{RC}$ in an out-of-hospital environment. In terms of performance, the slow speed of scope advancement due to automatic sequencing was the most consistently identified drawback of the RC. When that was investigated further, the majority of participants could see a role for RC in diagnostic procedures ( $\triangleright$ Table 2 ).

The questionnaire also assessed views regarding RC compared to standard colonoscopy. Participants were asked to identify and describe in their own words easier/more challenging and more/less intuitive aspects of RC. The RC received positive feedback for being less physical to handle and operate from seven participants $(77.78 \%)$. It was perceived that it could be mastered relatively easily, with additional exposure. Specific aspects of RC that were perceived to be more intuitive compared to standard colonoscopy were identification of the appropriate direction of movement and setup of the controller. Slow speed was noted as a consistent feature of RC ( $55.56 \%$ participants). Intermittent or occasional suboptimal views were also described as a drawback in comparison to standard colonoscopy (22.22\% participants). Aspects of RC that were perceived to be least intuitive compared to standard colonoscopy related to unfamiliarity with joy-stick controller and lack of manual control over probe position (44.44\%). Less experienced participants felt comfortable with using RC for any diagnostic procedure. The experts made suggestions for RC to be used for specific patient groups: cases in which people experienced too much discomfort from standard colonoscopy, or low-risk patients.

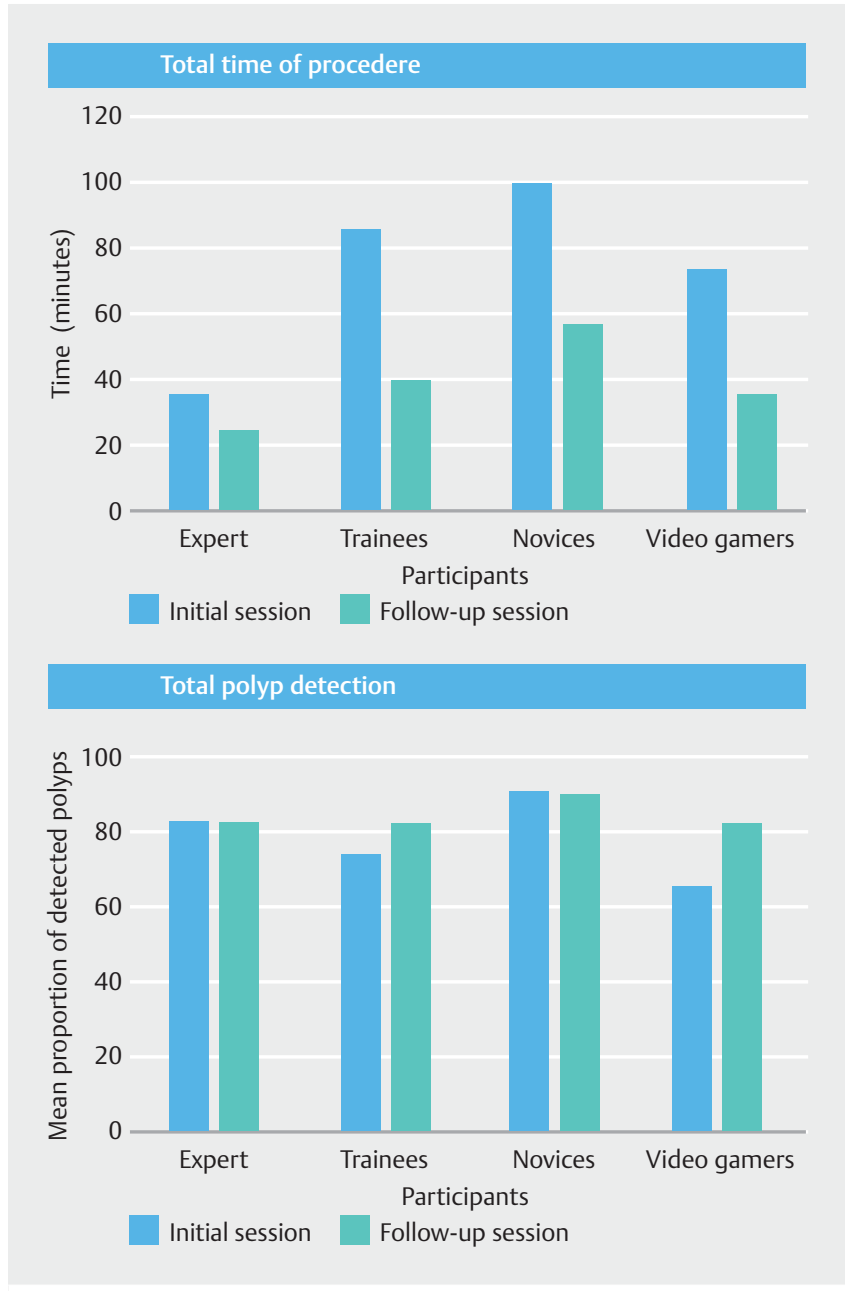

- Fig. 6 Comparison of participant performance between initial and follow-up session. One participant from each category took part in the follow-up session.

\section{Discussion}

In this study, we assessed operator acceptability and skill acquisition with the new RC. The results show that all participant groups were able to complete colonoscopy within the setting of a training simulator, as summarized in $>$ Table 3 . The overall polyp recognition rate by the participants was comparable to a similar study using a different RC with a joy-stick controller [7]. Cecal intubation time was generally longer than that expected with conventional colonoscopy, which may reflect the completely different skills involved in the precise control mechanisms of the RC procedure.

Our pilot data suggest that RC use may be worthy of investigation in a primary or intermediate care setting. Use of a semiautomated robotic device seems to have potential for improving diagnostics, expanding training programs and facilitating management of "difficult cases." The study suggests that participants using this interface seem to rapidly improve their performance, regardless of previous colonoscopy experience in this small cohort. 
- Table 1 Subjective evaluation of experience with robotic colonoscope.

\begin{tabular}{|c|c|c|c|c|c|}
\hline \multirow[t]{2}{*}{ Statement } & \multirow{2}{*}{$\begin{array}{l}\text { Total sample } \\
(n=9) \\
\text { n (\%) }\end{array}$} & \multicolumn{4}{|c|}{ Participant expertise } \\
\hline & & $\begin{array}{l}\text { Expert } \\
(n=3)\end{array}$ & $\begin{array}{l}\text { Trainee } \\
(n=2)\end{array}$ & $\begin{array}{l}\text { Novice } \\
(\mathrm{n}=2)\end{array}$ & $\begin{array}{l}\text { Gamer } \\
(n=2)\end{array}$ \\
\hline \multicolumn{6}{|l|}{ Where do you think the robotic colonoscopy could be best used? } \\
\hline - Hospital & $3(33 \%)$ & 0 & 1 & 0 & 2 \\
\hline - Out of hospital (e.g primary care) & $5(56 \%)$ & 2 & 1 & 2 & 0 \\
\hline - Neither & $1(11 \%)$ & 1 & 0 & 0 & 0 \\
\hline \multicolumn{6}{|c|}{ If this new device was available for clinical use currently and if you were given appropriate training would you: } \\
\hline $\begin{array}{l}\text { - Be happy to use it for some indications, but not all proce- } \\
\text { dures? }\end{array}$ & $4(45 \%)$ & 2 & 1 & 0 & 1 \\
\hline - Not be happy to use it at all? & $4(45 \%)$ & 1 & 1 & 2 & 0 \\
\hline - Feel unqualified to answer? & $1(10 \%)$ & 0 & 0 & 0 & 1 \\
\hline \multicolumn{6}{|l|}{ Which of these two options is the greatest drawback for RC? } \\
\hline $\begin{array}{l}\text { - Wait for automatic sequencing as not entirely under manual } \\
\text { control }\end{array}$ & $7(78 \%)$ & 2 & 1 & 2 & 2 \\
\hline - Not able to get an appropriate controlled view & $1(11 \%)$ & 0 & 1 & 0 & 0 \\
\hline - Both & $1(11 \%)$ & 1 & 0 & 0 & 0 \\
\hline \multicolumn{6}{|c|}{ Would training on the controller used for the RC be useful for people learning to use it? } \\
\hline - Yes & $6(67 \%)$ & 1 & 1 & 2 & 2 \\
\hline - No & $3(33 \%)$ & 2 & 1 & 0 & 0 \\
\hline
\end{tabular}

Intermittent suboptimal views described as a drawback in comparison to standard colonoscopy may be a feature related to training in and acquisition of skills with the RC. Perceived lack of control over movement could reflect current clinical practice of using standard colonoscopy, which enables great levels of control for clinicians with their hands. It seems this apparent lack of control is viewed negatively. Further challenges may be related to adapting to the joy-stick controller and the button functions. Console familiarity and experience of using joystick-controlled mechanisms may need further standardization at baseline in future follow-up studies. Wide variation in participants' outcomes may be a result of multiple individual factors and the reasons for it may become clearer in a larger cohort.

The limitations of the study were its small sample size and relatively limited follow-up data. The primary aim was to assess operator acceptability with the new device. Ideally, the sample size would be larger, with more participants in each study group. Another limitation was lack of direct comparison between RC and standard colonoscopy on the simulation-based training model and, therefore, lack of ability to comment on RC parameters such as procedure time or polyp detection. However, as a pilot study to test acceptability of the RC, this study shows interesting potential of robotics in the field of colonoscopy.
- Table 2 Evaluation of potential future use of RC.

Statement

Average rank

How do you think the robotic colonoscopy could be best used? (rank 1-3, one indicates most preferred) ${ }^{1}$

\begin{tabular}{l|l|}
\hline $\begin{array}{l}\text { - Training } \\
\text { - Diagnostic procedure to reassure and exclude } \\
\text { normal cases, and take biopsies }\end{array}$ & 1.7 \\
\hline - Cases where the patients have been very sensi- \\
tive to discomfort at standard colonoscopy
\end{tabular}

\section{Conclusion}

By assessing acceptability of the new device by operators with varying degrees of knowledge and experience, this project is the first step in assessment of specific training needs and development of a training program in robotic endoscopy. We are currently engaged in a pilot evaluation of the feasibility and acceptability of this technology in a patient cohort, which will assess whether skills acquired on the simulator will translate to similar outcomes in patients. 
- Table 3 Summary of participant outcomes.

\begin{tabular}{|c|c|c|c|c|c|c|c|c|c|}
\hline Parameter & Expert 1 & Expert 2 & Expert 3 & $\begin{array}{l}\text { Inter- } \\
\text { mediate } \\
1\end{array}$ & $\begin{array}{l}\text { Inter- } \\
\text { mediate } \\
2\end{array}$ & Novice 1 & Novice 2 & $\begin{array}{l}\text { Video } \\
\text { gamer } 1\end{array}$ & $\begin{array}{l}\text { Video } \\
\text { gamer } 2\end{array}$ \\
\hline $\begin{array}{l}\text { Cecal intubation time? } \\
\text { (minutes) }\end{array}$ & 20.6 & 44.7 & 24.6 & 26.2 & 75.9 & 62.8 & 24.1 & 57.6 & 24.5 \\
\hline Withdrawal time? (minutes) & 15.0 & 19.7 & 20.6 & 17.3 & 22.6 & 22.2 & 33.2 & 15.7 & 11.3 \\
\hline Total time? (minutes) & 35.6 & 64.4 & 45.2 & 43.5 & 98.5 & 85.0 & 57.3 & 73.3 & 35.8 \\
\hline $\begin{array}{l}\text { Number of lesions detected } \\
\text { during probe insertion? }\end{array}$ & $8(67 \%)$ & $7(58 \%)$ & $7(58 \%)$ & $8(67 \%)$ & $8(67 \%)$ & $6(50 \%)$ & $7(58 \%)$ & $7(58 \%)$ & $8(67 \%)$ \\
\hline $\begin{array}{l}\text { Number of lesions detected } \\
\text { during probe withdrawal? }\end{array}$ & $10(83 \%)$ & $10(83 \%)$ & $10(83 \%)$ & $10(83 \%)$ & $9(75 \%)$ & $9(75 \%)$ & $11(92 \%)$ & $6(50 \%)$ & $11(92 \%)$ \\
\hline $\begin{array}{l}\text { Total number of detected } \\
\text { lesions? (\%) }\end{array}$ & $10(83 \%)$ & $11(92 \%)$ & $10(83 \%)$ & $10(83 \%)$ & $11(92 \%)$ & $9(75 \%)$ & $11(92 \%)$ & $8(67 \%)$ & $11(82 \%)$ \\
\hline $\begin{array}{l}\text { Number of colonoscopies } \\
\text { performed? }\end{array}$ & $>5000$ & $>1000$ & $>5000$ & 35 & 40 & 0 & 0 & 0 & 0 \\
\hline
\end{tabular}

\section{Acknowledgements}

Cancer Research UK, Welsh Institute of Minimal Access Therapy, Mr. K. Arnoutakis, Partners for Endoscopy and Endotics (Era Endoscopy s.r.l) for technical assistance

\section{Competing interests}

None

References

[1] Haggar FA, Boushey RP. Colorectal cancer epidemiology: incidence, mortality, survival, and risk factors. Clin Colon Rectal Surg 2009; 22: $191-197$

[2] Logan RFA, Patnick J, Nickerson C et al. Outcomes of the Bowel Cancer Screening Programme (BCSP) in England after the first 1 million tests. Gut 2012; 61: 1439-1446
[3] Christou A, Katzenellenbogen JM, Thompson SC. Australia's National Bowel Cancer Screening Program: does it work for Indigenous Australians? BMC Public Health 2010; 10: 1-21

[4] Geiger TM, Ricciardi R. Screening options and recommendations for colorectal cancer. Clin Colon Rectal Surg 2009; 22: 209-17

[5] Bujanda L, Sarasqueta C, Zubiaurre L et al. Low adherence to colonoscopy in the screening of first-degree relatives of patients with colorectal cancer. Gut 2007; 56: 1714-1718

[6] Tumino E, Sacco R, Bertini M et al. Endotics system vs colonoscopy for the detection of polyps. World J Gastroenterol 2010; 16: 5452 - 5456

[7] Rozeboom E, Ruiter J, Franken $M$ et al. Intuitive user interfaces increase efficiency in endoscope tip control. Surg Endosc 2014; 28: $2600-2605$

[8] Rozeboom ED, Broeders IAM], Fockens P. Feasibility of joystick guided colonoscopy. J Robot Surg 2015; 9: 173-178

[9] Cosentino F, Tumino E, Rubis Passoni G et al. Functional evaluation of the Endotics System, a new disposable self-propelled robotic colonoscope: in vitro tests and clinical trial. Int J Artif Organs 2009; 32: 517 527

[10] Ansell ], Arnaoutakis K, Goddard S et al. The WIMAT colonoscopy suitcase model: a novel porcine polypectomy trainer. Colorectal Disease $2013 ; 15: 217-223$ 